\title{
ВЗАИМОДЕЙСТВИЕ МЕСТНЫХ ОРГАНОВ ВЛАСТИ И НАЛОГОВЫХ ОРГАНОВ ПРИ ВЫЯВЛЕНИИ БЕСХОЗЯЙНЫХ И СОКРЫТЫХ ОТ УЧЕТА ОБЪЕКТОВ НЕДВИЖКИМОСТИ
}

\begin{abstract}
АНнОТАЦИЯ. Статья посвящена проблеме выявления и постановки на учет неучтенного имущества организаций. Исследуются причины, в связи с которыми имущество может быть не поставлено на учет. Систематизируется информация, доказывающая наличие неучтенного имущества и его использование в хозяйственной деятельности. Предлагается механизм включения неучтенных объектов в налогооблагаемую базу по налогу на имущество. Ключевая роль в предлагаемом механизме отведена муниципальным органам власти и налоговым органам. Предложено также комбинировать три способа выявления неучтенных объектов недвижимости: использование аэрофотосъемки и соотнесение ее к сведениям государственного кадастра; выездные проверки налоговых органов; осмотр, и обход объектов недвижимости муниципальными органами власти. В целях выявления и постановки на учет объектов недвижимости разработаны предложения по организации взаимодействия различных органов на следующих этапах: координация, совместная деятельность, сотрудничество, координация и совместная деятельность, совместная работа, контроль.

кЛючЕВЫЕ словА. Налоговые органы; налоговый контроль; межведомственное взаимодействие; местное самоуправление; неучтенные объекты недвижимости. ИНФОРМАЦИЯ О СТАТЬЕ. Дата поступления 6 марта 2017 г.; дата принятия к печати 20 марта 2017 г.; дата онлайн-размещения 31 марта 2017 г.
\end{abstract}

O. V. Baturina Baikal State University, Irkutsk, Russian Federation

E. S. Khoroshavina Baikal State University, Irkutsk, Russian Federation

\section{INTERACTION OF LOCAL AUTHORITIES AND TAX BODIES IN IDENTIFYING ABANDONED AND HIDDEN OBJECTS OF REAL ESTATE}

\begin{abstract}
The article is devoted to the problem of identifying and registering unrecorded property of organizations. It explores the grounds of the factors why the property cannot be registered. It systemizes the information that proves availability of the unregistered property and its use in economic activities. It offers a mechanism of including the unregistered objects into the property tax taxation basis. The key role in this mechanism is given to municipal authorities and tax bodies. It also offers to combine three ways of identifying the unregistered real estate objects: use of aero photography and its reference in informing the state cadaster; on-site inspection by tax bodies and walkabout of real estate objects by municipal authorities. In order to identify and register the real estate objects, the article works out proposals on organizing interactions of different bodies at the following stages: coordination, joint activity, cooperation, coordination and joint activity, teamwork, control.

KEYWORDS. Tax authorities; tax control; interagency cooperation; local self-government; unregistered objects of real estate.

ARTICLE INFO. Received March 6, 2017; accepted March 20, 2017; available online March 31, 2017.
\end{abstract}

(C) О. В. Батурина, Е. С. Хорошавина, 2017

\section{Baikal Research Journal}


Вопросы взаимодействия налоговых органов с другими государственными органами, органами местного самоуправления не так широко рассматриваются в экономической литературе, как другие проблемы налогового администрирования и контроля.

Общим вопросам взаимосвязи органов местного самоуправления и органов государственной власти посвящена статья А. Ф. Бортника [1], который обращает внимание на постоянную связь и взаимодействие различных органов власти. М. Ю. Каверзин [2] подчеркивает трактовку органов государственного управления и органов местного самоуправления как элементов единой системы социального управления, публичной власти, обеспечивающей жизнедеятельность общества как единого целого. Х. М. Мусаева, С. И. Сиражудинова [3] считают межведомственное взаимодействие налоговых органов с другими органами исполнительной власти одним из факторов повышения эффективности налогового контроля.

Взаимодействие налоговых органов с различными государственными, региональными и муниципальными органами признается одним из условий реализации функций налогового администрирования [4, с. 10]. В этом контексте В. М. Минеева, Н. Г. Идиатулов [5], а также А. Ш. Кузулгуртова [6] рассматривают формы взаимодействия налоговых органов с другими государственными органами: совместные контрольные мероприятия, обмен информацией, создание межведомственных комиссий и рабочих групп из представителей ведомств, проведение совместных коллегий, совещаний и т. д., а также уделяют внимание развитию налогового контроля по выявленным направлениям, системному взаимодействию и взаимосвязи мероприятий между собой.

Наибольшее внимание традиционно отводится взаимодействию налоговых органов с иными государственными органами в сфере противодействия уклонению от уплаты налогов [7-10]. При этом, некоторые авторы обращают внимание на проблемы, возникающие в процессе налогового контроля. Так, обращается внимание, что усиление административного давления на бизнес, расширение полномочий ведомств, контролирующих хозяйственную деятельность, способно существенно замедлить экономический рост [11], указывается также на проблему недостатка финансовых и материальных средств у органов местного самоуправления, что не позволяет им полностью реализовывать свои компетенции [12]. В этой связи, у органов власти территорий и органов местного самоуправления возникает заинтересованность в более тесном взаимодействии с налоговыми органами в сфере имущественного налогообложения, отмеченная в работах Е. А. Власенковой [13] А. В. Евдокимовой [14], Н. В. Фадейкиной [15].

В статье рассматривается взаимодействие налоговых и иных государственных органов в сфере контроля за правильностью исчисления налога на имущество организаций. Данный налог является региональным и по решению субъекта может распределяться в пользу местных бюджетов. Распределение в пользу местных бюджетов позволит стимулировать местные органы власти к более активным действиям по выявлению объектов недвижимости не поставленных на учет и не облагаемых налогом. Однако такие действия приведут к результату только в случае организации эффективного взаимодействия с налоговыми органами и органами, обладающими информацией о имуществе.

Занижение налогооблагаемой базы по налогу на имущество организаций носит системный характер и во многом определяется общими условиями ведения бизнеса и уклонением от уплаты налогов в целом. Неотражение имущества организации на ее балансе организации может быть вызвано несколькими причинами:

- недвижимое имущество не зарегистрировано в установленном порядке в связи с какими-либо нарушениями в процессе строительства (которые могут иметь объективный характер или возникать не по вине налогоплательщика);

\section{Baikal Research Journal}

электронный научный журнал Байкальского государственного университета 
- недвижимое имущество не поставлено на учет собственно с целью минимизации налога на имущество и учтено на счете 08 (капитальные вложения);

- недвижимое имущество не зарегистрировано в связи с его самовольным возведением. Фактически самовольные постройки, если они не затрагивают частных интересов, не сносятся. Негативным последствием такого положения вещей является легальное уклонение от уплаты налога на имущество фактических владельцев самовольных построек.

- применяется схема разделения крупного бизнеса на несколько отдельных организаций, являющихся малыми предприятиями и не уплачивающими налог на имущество;

- недвижимое имущество зарегистрировано на организацию, применяющую УСН, которая сдает имущество в аренду в целях избежания налога на имущество.

Таким образом, причины неотражения недвижимого имущества на балансе могут быть разнообразными (так как сфера строительства часто связана с нарушениями) однако, имущество при этом реально существует и может быть выявлено. Источники информации о возможных неучтенных объектах представлены в табл. 1.

Таблица 1

\section{Источники информации о неучтенных объектах}

\begin{tabular}{|c|c|c|}
\hline $\begin{array}{c}\text { Орган, располагающий } \\
\text { информацией }\end{array}$ & Вид информации & $\begin{array}{c}\text { Возможное использование } \\
\text { информации для выявления } \\
\text { неучтенных объектов }\end{array}$ \\
\hline \multirow[t]{2}{*}{ Налоговые органы } & $\begin{array}{l}\text { Данные о месте нахождения предста- } \\
\text { вительств и филиалов, обладающих } \\
\text { имуществом }\end{array}$ & $\begin{array}{l}\text { Для получения сведений о } \\
\text { распределении имущества } \\
\text { по филиалам }\end{array}$ \\
\hline & $\begin{array}{l}\text { Сведения о зарегистрированных кон- } \\
\text { трольно-кассовых машинах и адресах } \\
\text { их установки }\end{array}$ & $\begin{array}{l}\text { Для получения сведений о } \\
\text { месте нахождения недвижи- } \\
\text { мого имущества в котором } \\
\text { находится ККМ }\end{array}$ \\
\hline $\begin{array}{l}\text { Росреестр и его территори- } \\
\text { альные органы }\end{array}$ & $\begin{array}{l}\text { Сведения о принадлежности недвижи- } \\
\text { мого имущества, в том числе, нахо- } \\
\text { дящегося в собственности иных лиц } \\
\text { (право аренды. хозяйственного ведения, } \\
\text { постоянного бессрочного пользования } \\
\text { земельным участком и т. п.) }\end{array}$ & $\begin{array}{l}\text { Для получения сведений о } \\
\text { месте нахождения объектов } \\
\text { недвижимости }\end{array}$ \\
\hline $\begin{array}{l}\text { Земельная кадастровая } \\
\text { палата }\end{array}$ & $\begin{array}{l}\text { Данные о земельных участках, зданиях, } \\
\text { сооружениях, помещениях, объектах } \\
\text { незавершенного строительства }\end{array}$ & $\begin{array}{l}\text { Для выявления объектов, } \\
\text { не зарегистрированных в } \\
\text { Управлении Росреестра } \\
\end{array}$ \\
\hline $\begin{array}{l}\text { Федеральная служба по } \\
\text { экологическому, техно- } \\
\text { логическому и атомному } \\
\text { надзору (Ростехнадзор) }\end{array}$ & $\begin{array}{l}\text { Сведения об оборудовании, представля- } \\
\text { ющем опасность при использовании }\end{array}$ & $\begin{array}{l}\text { Для выявления имущества, } \\
\text { связанного с данным обору- } \\
\text { дованием }\end{array}$ \\
\hline $\begin{array}{l}\text { Государственная инспек- } \\
\text { ция по надзору за техниче- } \\
\text { ским состоянием самоход- } \\
\text { ных машин и других видов } \\
\text { техники (Гостехнадзор) }\end{array}$ & $\begin{array}{l}\text { Сведения о технике и других механиз- } \\
\text { мах, требующих специального учета и } \\
\text { надзора за их эксплуатацией } \\
\end{array}$ & $\begin{array}{l}\text { Для выявления имущества, } \\
\text { связанного с использованием } \\
\text { таких машин и механизмов }\end{array}$ \\
\hline Страховые компании & $\begin{array}{l}\text { Сведения о заключении договоров } \\
\text { страхования, в том числе страхования } \\
\text { имущества, времени его действия } \\
\end{array}$ & $\begin{array}{l}\text { Для выявления застра- } \\
\text { хованного имущества, не } \\
\text { поставленного на учет }\end{array}$ \\
\hline $\begin{array}{l}\text { Банки, кредитные учреж- } \\
\text { дения Бюро кредитных } \\
\text { историй }\end{array}$ & $\begin{array}{l}\text { Сведения о получении кредитов и } \\
\text { переданном в залог в обеспечение их } \\
\text { возврата имуществе }\end{array}$ & $\begin{array}{l}\text { Для выявления имущества } \\
\text { не поставленного на учет, яв- } \\
\text { ляющегося предметом залога }\end{array}$ \\
\hline \multirow[t]{2}{*}{$\begin{array}{l}\text { Органы местного самоу- } \\
\text { правления }\end{array}$} & $\begin{array}{l}\text { Сведения о выделенных земельных } \\
\text { участках и их целевом назначении }\end{array}$ & \multirow{2}{*}{$\begin{array}{l}\text { Для выявления объектов } \\
\text { недвижимого имущества, не } \\
\text { поставленных на учет } \\
\end{array}$} \\
\hline & $\begin{array}{l}\text { Реестры выданных разрешений на строи- } \\
\text { тельство, ввод объектов в эксплуатацию, } \\
\text { подключение к инженерным сетям }\end{array}$ & \\
\hline
\end{tabular}

\section{Baikal Research Journal}

электронный научный журнал Байкальского государственного университета 
Предлагаемый механизм включения объектов недвижимого имущества в налоговую базу заключается в использовании нескольких источников информации:

- сведений из реестров выданных разрешений на строительство, которые ведут муниципальные органы;

- сведений Управления Россреестра о зарегистрированных объектах недвижимости и их характеристиках;

- данных Управления Федеральной налоговой службы об объектах налогообложения налогом на имущество организаций.

На рис. 1 показаны три возможных способа выявления незарегистрированных объектов недвижимости.

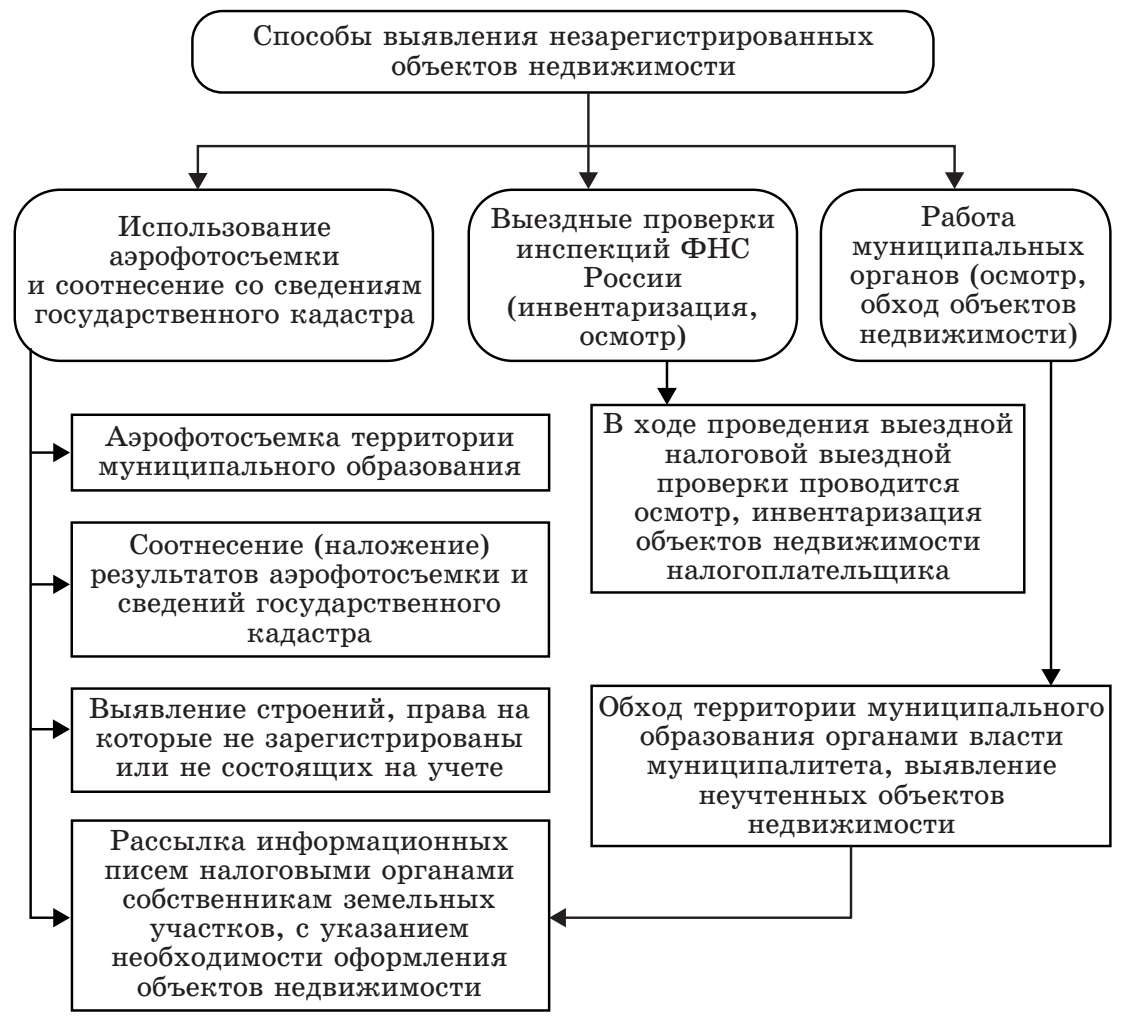

Рис. 1. Предлагаемый механизм выявления незарегистрированных объектов недвижимости

Первый способ - использование аэрофотосъемки и соотнесение ее к сведениям государственного кадастра. Для его внедрения необходима разработка специальной информационной системы, которая представляла бы собой свод нескольких баз данных - так называемых слоев.

Первый слой информации - это подробная карта аэрофотосъемки, которая позволяет достичь более детализированного отображения, на которой будет заметен каждый объект недвижимости. Второй слой информации - база государственного кадастра. При совмещении двух слоев, происходит сравнение реальных данных со сведениями, внесенными в кадастр. Помимо этого, система должна давать возможность отправки мгновенного автоматического запроса данных в Росреестр о правах на объекты недвижимости, а также учитывать информацию налоговых органов об учете объектов по налогу на имущество организаций.

\section{Baikal Research Journal}


После обработки аэрофотосъемки и совмещения полученной информации со сведениями государственного кадастра (сверкой со сведениями ЕГРН и архивами БТИ) на карте отмечаются строения, не стоящие на учете или права на которые не зарегистрированы.

Органом власти, осуществляющим аэрофотосъемку и дальнейшую обработку полученной информации, может выступить Министерство имущественных отношений Иркутской области.

Далее следует этап работы с налогоплательщиками. В их адрес местной инспекции УФНС направляется обращение о необходимости оформления объекта недвижимости и оплаты задолженности по налогу. $\kappa$ письму прилагается подробное описание списка необходимых документов, а также выписка из Росреестра и фотоплан участка - в подтверждение предъявляемых претензий. Если регистрации недвижимости не происходит, то в адрес нарушителя направляется повторное обращение - уже с приглашением на заседание профильной Межведомственной комиссии. Апробация данного способа выявления неучтенных объектов уже началась в Московской области.

Второй способ - это проведение выездных проверок налоговых органов, во время проведения которых могут использоваться инвентаризация, осмотр, опрос, привлечение специалиста, экспертиза. В ходе проведения налоговой проверки должностными лицами налогового органа проверяются, анализируются, сопоставляются и оцениваются документы и информация, имеющие значение для формирования выводов о правильности исчисления, удержания и уплаты (перечисления) налогов и сборов, в том числе проводится осмотр, инвентаризация объектов основных средств и иного имущества, опрос. Осмотр - это предварительная стадия выявления незарегистрированных объектов недвижимости. Инвентаризация объектов основных средств и иного имущества проводится налоговыми органами для выявления основных средств или иного имущества, не отраженных в бухгалтерском учете налогоплательщика. Инвентаризация, опрос, привлечение специалиста, экспертиза используются на стадии сбора доказательной базы о наличии объектов, подлежащих налогообложению.

Третий способ - работа муниципальных органов власти (осмотр, обход объектов недвижимости). Данный способ выявления незарегистрированных объектов недвижимости заключается в том, что местные органы власти производят физический обход территории муниципального образования, с целью выявления неучтенных объектов недвижимости.

Предлагаемые способы должны применяться совместно и составлять единый механизм выявления незарегистрированных объектов недвижимости.

Ключевую роль в выявлении имущества, не поставленного на учет, должны играть муниципалитеты:

- органы местного самоуправления выдают разрешения на строительство и ведут реестр выданных разрешений. Соответственно, они же и должны контролировать степень завершенности объекта недвижимости;

- местные органы имеют все возможности для контроля и выявления незаконного строительства на подведомственной им территории;

- местные бюджеты пойдут доходы от выявления скрытого имущества.

Предлагаемый комплекс мероприятий по выявлению незарегистрированных объектов недвижимости может быть осуществлен лишь при тесном и плодотворном взаимодействии следующих субъектов: Управления Федеральной службы государственной регистрации, кадастра и картографии по Иркутской области, органов БТИ, Министерства имущественных отношений Иркутской области, УФНС по Иркутской области, органов местного самоуправления.

\section{Baikal Research Journal}


Взаилодействие - это деятельное проявление субъектов (участников) взаимодействия, согласованное по цели, основанное на кооперации, деловом сотрудничестве и взаимопомощи в интересах решения их общих задач. По мнению многих специалистов, «стерильная чистота» разделения властей является ненужной и до сих пор не воспринята ни одним государством. Между органами власти не может и не должно быть непроходимой преграды. Они должны иметь возможность взаимодействовать и контролировать друг друга в целях эффективного управления, а также с тем, чтобы не допустить опасной концентрации полномочий в руках одной из ветвей власти.

В целях выявления и постановки на учет объектов недвижимости предлагаются следующие этапы взаимодействия органов власти: координация; совместная деятельность; сотрудничество; координация и совместная деятельность; совместная работа; контроль.

Координация предполагает, что существует взаимная связь между различными субъектами, среди которых выделяется один из нескольких более активных, заставляющих всю систему двигаться слажено и в одном направлении. На этапе координации предполагается сбор всех субъектов взаимодействия и получение ими рекомендаций от Министерства имущественных отношений Иркутской области.

Совлестная деятельность предполагает выполнение каждым органом власти определенной работы по решению общей задачи с использованием собственных ресурсов. На данном этапе каждый субъект взаимодействия выполняет подбор данных обо всех объектах недвижимости находящихся на территории Иркутской области:

- местные органы должны проверить сведения, находящиеся в Реестре выданных разрешений на строительство, на степень завершенности объектов недвижимости;

- Управление Федеральной службы государственной регистрации, кадастра и картографии по Иркутской области должно подготовить сведения о всех зарегистрированных объектах недвижимости на территории Иркутской области;

- налоговые органы должны подготовить информацию обо всех объектах, которые подлежат обложению налогом на имущество организаций.

Сотрудничество между органами власти предполагает деятельность в сфере совместного ведения. Чаще всего оно реализуется путем заключения соглашений между органами исполнительной власти о сотрудничестве в определенной сфере. На данном этапе местные органы заключают соглашение о сотрудничестве с Управлением Федеральной службы государственной регистрации, кадастра и картографии Иркутской области о предоставлении информации о зарегистрированных на территории конкретного муниципального района объектах недвижимого имущества.

Местные органы должны сверить информацию о нежилых объектах недвижимости, находящихся на подведомственной им территории, содержащуюся в Реестре выданных разрешений на строительство, с информацией, полученной из Росреестра. Сопоставить полученную информацию (возможная форма сопоставления в табл. 2), выявить причины расхождений.

Сводный реестр нежилых объектов недвижимости

Таблица 2

\begin{tabular}{|c|c|c|c|c|c|}
\hline \multicolumn{3}{|c|}{ Выданные разрешения на строительство } & \multicolumn{3}{|c|}{ Государственная регистрация объекта } \\
\hline $\begin{array}{l}\text { Дата выдачи } \\
\text { разрешения }\end{array}$ & $\begin{array}{c}\text { Кадастровый } \\
\text { номер земель- } \\
\text { ного участка }\end{array}$ & $\begin{array}{c}\text { Технические } \\
\text { характеристики } \\
\text { и вид использова- } \\
\text { ния объекта }\end{array}$ & $\begin{array}{c}\text { Дата госу- } \\
\text { дарственной } \\
\text { регистрации }\end{array}$ & $\begin{array}{l}\text { Кадастровый } \\
\text { номер объекта } \\
\text { недвижимости }\end{array}$ & $\begin{array}{l}\text { Номер госу- } \\
\text { дарственной } \\
\text { регистрации }\end{array}$ \\
\hline
\end{tabular}

\section{Baikal Research Journal}


Координация и совместная деятельность. Министерство имущественных отношений Иркутской области должно проанализировать полученные данные о нежилых объектах недвижимости. Дать поручение местным органам власти произвести обход территории муниципального образования, с целью выявления самовольно возведенных нежилых объектов недвижимости. В это же время, производится запуск беспилотных летательных объектов для аэрофотосъемки. Анализируются данные аэрофотосъемки, выявляются самовольно возведенные объекты недвижимости на территории Иркутской области.

Совместная работа. Это этап непосредственной работы с гражданами: в их адрес направляется обращение местного налогового органа о необходимости оформления объекта недвижимости и оплаты налога. На это отводится срок четыре месяца, возможность сдать документы предоставляется через МФЦ.

Контроль. Создается межведомственная комиссия из субъектов взаимодействия (Министерство имущественных отношений Иркутской области, местных органов власти, Росреестра, УФНС, МВД). Если регистрации недвижимости не происходит, то в адрес нарушителя направляется повторное обращение -с приглашением на заседание Межведомственной комиссии.

Значительная работа по увеличению налогооблагаемой базы по налогу на имущество организаций отводится в предлагаемом механизме налоговым органам. В этом процессе могут возникать определенные сложности.

Налоговые органы в РФ - это федеральная служба, и подчиняется она соответственно федеральному центру. Поэтому приоритетное значение имеют показатели по налогам, зачисляемым в федеральный бюджет. Кроме того, начисления по крупным федеральным налогам - НДС, налог на прибыль, на порядок выше доначислений по региональным или местным налогам - налогу на имущество предприятий, транспортному или земельному налогам, а трудоемкость проверки одинаковая. Соответственно, при прочих равных обстоятельствах, приоритет в работе налоговых органов отдается федеральному бюджету.

Анализ показателей контрольной работы налоговых органов показывает, что эффективность проверок по региональным и местным налогам несколько ниже, чем по федеральным налогам. Доначисления по региональным налогам составляют всего $4 \%$ от общей суммы доначислений. Однако, результативность проверок по налогу на имущество в последние годы возросла (рис. 2).

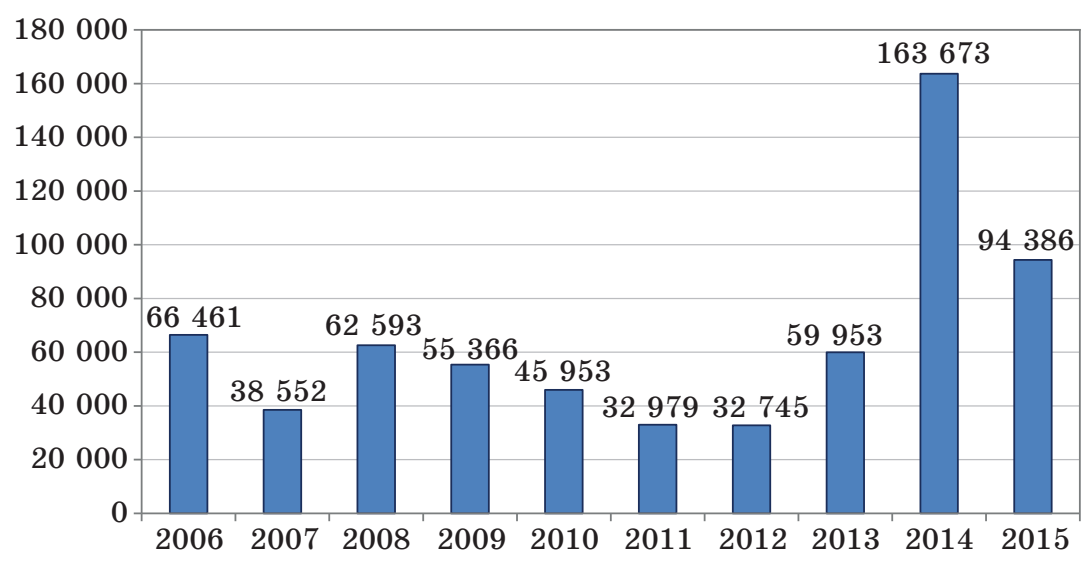

Рис. 2. Динамика доначислений по налогу на имущество организаций по результатам выездных и камеральных налоговых проверок, проводимых налоговыми органами Иркутской области, тыс. $p$.

\section{Baikal Research Journal}


Анализ результатов налогового контроля показывает, что ежегодно налоговыми органами производятся доначисления налога на имущество в среднем около 50 млн р. Наиболее результативными явились 2014 г. и 2015 г. по итогам которых доначисления составили более 163 млн р. и 94 млн р. соответственно.

Для того чтобы проверки по региональным и местным налогам были не менее, а более эффективными чем по федеральным налогам необходима заинтересованность работников налоговых органов. Существовавшая ранее система заключения договоров по стимулированию контрольной работы налоговых органов вызывала справедливые нарекания, но она давала результаты в виде дополнительных поступлений в местные бюджеты. Кроме того, налоговые органы могут быть заинтересованы в увеличении доначислений и взысканий по проверкам, так как это является показателем их эффективности.

\section{Список использованной литературы}

1. Бортник А. Ф. К вопросу о взаимосвязи государства и местного самоуправления / А. Ф. Бортник // Международный научно-исследовательский журнал. - 2014. — № 8 (27), ч. 2. - C. $62-64$.

2. Каверзин М. Ю. Государство и местное самоуправление: проблемы взаимодействия / М. Ю. Каверзин // Вестник Российского университета дружбы народов. Сер.: Политология. -2003 . - № 4 . - С. 13-19.

3. Мусаева Х. М. К вопросу о сущности дефиниций «Налоговый контроль» и оценке резервов роста налоговых доходов / Х. М. Мусаева, С. И. Сиражудинова // Международный бухгалтерский учет. - 2013. - № 14 . - С. 38-45.

4. Энциклопедия теоретических основ налогообложения / под ред. И. А. Майбурова, Ю. Б. Иванова. - М. : Юнити-Дана, 2016. - 503 с.

5. Минеева В. М. Взаимодействие налоговых органов и других государственных структур в ходе осуществления налогового контроля / В. М. Минеева, Н. Г. Идиатулов // Современная наука: теоретический и практический взгляд : материалы Междунар. науч.-практ. конф. - Уфа : Аэтерна, 2016. - С. 210-212.

6. Кузулгуртова А. Ш. Приоритеты развития государственного контроля налоговых правонарушений на современном этапе / А. Ш. Кузулгуртова // Бизнес. Образование. Право. Вестник Волгоградского института бизнеса. - 2012. - № 1. - С. 144-151.

7. Адигамова Ф. Ф. Межведомственное взаимодействие налоговых органов с правоохранительными органами / Ф. Ф. Адигамова, Г. В. Шацило // Казанский экономический вестник. - 2014. - № 6 (14). - С. 31-37.

8. Гергова 3. Х. Взаимодействие налоговых органов с органами внутренних дел при осуществлении налогового контроля / 3. Х. Гергова, 3. Н. Ягумова // Актуальные вопросы современной науки. - 2015. - № 4 (8). - С. 52-56.

9. Киреенко А. П. Развитие налогообложения индивидуальных предпринимателей и борьба с уклонением от уплаты налогов / А. П. Киреенко, М. Е. Климова // Регион: экономика и социология. - 2012. - № 1. - С. 142-159.

10. Филиппова Н. А. Информационное взаимодействие органов внутренних дел и налоговых органов по выявлению налоговых правонарушений / Н. А. Филиппова, М. С. Лебина // Налоговая политика и практика. - 2011. - № 5-1. - С. 12-14.

11. Татаркин А. И. Формирование оптимального комплекса мер по противодействию теневой экономике на основе сценарного анализа / А. И. Татаркин, А. А. Куклин, Г. А. Агарков // Экономика региона. - 2008. - № 2. - С. 9-22.

12. Левушкина С. В. Пути совершенствования бюджетной и налоговой системы на муниципальном уровне / С. В. Левушкина, Р. В. Мирошниченко // Ученые записки Российского государственного социального университета. - 2009. - № 6. - С. 83-87.

13. Власенкова Е. А. Имущественные налоги как источник доходов бюджетов субфедерального уровня: проблемы и перспективы / Е. А. Власенкова // Финансы и кредит. 2011. - № 6 (438). - C. 74-79.

14. Евдокимова А. В. Налогообложение недвижимости физических лиц: взаимодействие налоговых органов и органов МСУ / А. В. Евдокимова // Перспективы развития

\section{Baikal Research Journal}


российского государства и общества в современных условиях : материалы Междунар. науч.-практ. конф. Саратов, 12 дек. 2014 г. / В. Л. Чепляев [и др.]. - Саратов : Поволж. ин-т упр. им. П. А. Столыпина, 2015. - С. 120-122.

15. Развитие инструментария взаимодействия субъектов системы публичного управления социально-экономическим развитием территории / под ред. Н. В. Фадейкиной. - Новосибирск : Сиб. акад. финансов и банк. дела, 2012. - С. 126-144.

\section{References}

1. Bortnik A. F. On issue of interrelation of state and local government. Mezhdunarodnyi nauchno-issledovatel'skii zhurnal = International Research Journal, 2014, no. 8 (27), pr. 2, pp. 62-64. (In Russian).

2. Kaverzin M. Yu. State and local government: the problems of coordination. Vestnik Rossiiskogo universiteta druzhby narodov. Seriya: Politologiya = Bulletin of Peoples' Friendship University of Russia. Series: Politology, 2003, no. 4, pp. 13-19. (In Russian).

3. Musaeva Kh. M., Sirazhudinova S. I. On issue of essence of definitions «tax control» and assessment of tax revenue growth reserves. Mezhdunarodnyi bukhgalterskii uchet $=$ International Accounting, 2013, no. 14, pp. 38-45. (In Russian).

4. Maiburov I. A. Ivanov Yu. B. (eds). Entsiklopediya teoreticheskikh osnov nalogooblozheniya [Encyclopedia of theoretical basics of taxation]. Moscow, Yuniti-Dana Publ., 2016. $503 \mathrm{p}$.

5. Mineyeva V. M., Idiatulov N. G. Interaction of tax bodies and other governmental structures in the course of implementing tax control. Sovremennaya nauka: teoreticheskii $i$ prakticheskii vzglyad. Materialy Mezhdunarodnoi nauchno-prakticheskoi konferentsii [Modern science: theoretical and practical outlook. Materials of International Research Conference]. Ufa, Aeterna Publ., 2016, pp. 210-212. (In Russian).

6. Kuzulgurtova A. Sh. Development priorities for state control of tax violations at the present-day stage. Biznes. Obrazovanie. Pravo. Vestnik Volgogradskogo instituta biznesa = Business. Education. Law. Bulletin of Volgograd Business Institute, 2012, no. 1, pp. $144-151$. (In Russian).

7. Adigamova F. F., Shatsilo G. V. Interagency cooperation of tax authorities with law enforcement authorities. Kazanskii ekonomicheskii vestnik = Kazan Economic Bulletin, 2014, no. 6 (14), pp. 31-37. (In Russian).

8. Gergova Z. Kh., Yagumova Z. N. Interaction of tax bodies with internal affairs bodies in performing tax control. Aktual'nye voprosy sovremennoi nauki = Actual Issues of Modern Science, 2015, no. 4 (8), pp. 52-56. (In Russian).

9. Kireyenko A. P., Klimova M. E. Improving taxation of sole proprietors and measures against tax evasion. Region: ekonomika i sotsiologiya = Region: Economics and Sociology, 2012, no. 1, pp. 142-159. (In Russian).

10. Filippova N. A., Lebina M. S. Information interaction of internal affairs bodies and taxation bodies in identifying tax violations. Nalogovaya politika i praktika = Tax Policy and Practice, 2011, no. 5-1, pp. 12-14. (In Russian).

11. Tatarkin A. I., Kuklin A. A., Agarkov G. A. Scene analysis as a basis of optimal actions against shadow economy. Ekonomika regiona =Regional Economy, 2008, no. 2, pp. 9-22. (In Russian).

12. Levushkina S. V., Miroshnichenko R. V. Ways of improving budget and taxation systems at municipal level. Uchenye zapiski Rossiiskogo gosudarstvennogo sotsial'nogo universiteta = Scholarly Notes of Russian State Social University, 2009, no. 6, pp. 83-87. (In Russian).

13. Vlasenkova E. A. Property taxes as a revenue source for budgets of sub-federal level: problems and prospects. Finansy $i$ kredit $=$ Finance and Credit, 2011, no. 6 (438), pp. 74-79. (In Russian).

14. Yevdokimova A. V. Taxation of individuals' real estate: interaction of tax bodies and local government bodies. In Cheplyaev V. L. et al. Perspektivy razvitiya rossiiskogo gosudarstva $i$ obshchestva $v$ sovremennykh usloviyakh. Materialy Mezhdunarodnoi nauchno-prakticheskoi konferentsii. Saratov, 12 dekabrya $2014 \mathrm{~g}$. [Prospects of developing the Russian state in the current context. Materials of International Research Conference. Saratov, December 12, 2014]. Saratov, P. A. Stolypin Volga Region Institute of Administration Publ., 2015, pp. 120-122. (In Russian).

\section{Baikal Research Journal}


15. Fadeikina N. V. (ed.). Razvitie instrumentariya vzaimodeistviya sub"ektov sistemy publichnogo upravleniya sotsial'no-ekonomicheskim razvitiem territorii [Developing tools of interacting the subjects of public management system for socio-economic development of the territory]. Novosibirsk, Siberian Academy of Finance and Banking Publ., 2012, pp. 126-144. (In Russian).

\section{Информация об авторах}

Батурина Ольга Викторовна - кандидат экономических наук, доцент, кафедра финансов, кредита и бухгалтерского учета, Читинский институт, Байкальский государственный университет, 672000, г. Чита, ул. Анохина, 56, e-mail: baturina_80@mail.ru.

Хорошавина Екатерина Сергеевна - аспирант, кафедра налогов и таможенного дела, Байкальский государственный университет, 664003, г. Иркутск, ул. Ленина, 11, e-mail: kireenko.e@list.ru.

\section{Authors}

Olga V. Baturina - PhD in Economics, Associate Professor, Chair of Finance, Credit and Accounting, Chita Institute, Baikal Sate University, 56 Anokhin St., 672000, Chita, Russian Federation; e-mail: baturina_80@mail.ru.

Ekaterina S. Khoroshavina - PhD Student, Chair of Taxation and Customs, Baikal State University, 11 Lenin St., 664003, Irkutsk, Russian Federation; e-mail: kireenko.e@list.ru.

\section{Библиографическое описание статьи}

Батурина О. В. Взаимодействие местных органов власти и налоговых органов при выявлении бесхозяйных и сокрытых от учета объектов недвижимости / О. В. Батурина, Е. С. Хорошавина // Baikal Research Journal. - 2017. - T. 8, № 1. - DOI: 10.17150/2411$\underline{6262.2017 .8(1) .2 . ~}$

\section{Reference to article}

Baturina O. V., Khoroshavina E. S. Interaction of local authorities and tax bodies in identifying abandoned and hidden objects of real estate. Baikal Research Journal, 2017, vol. 8, no. 1. DOI: 10.17150/2411-6262.2017.8(1).2. (In Russian).

\section{Baikal Research Journal}

